\title{
COVID-19: Cultural Predictors of Gender Differences in Global Prevalence Patterns
}

\author{
Olav T. Muurlink ${ }^{1}$ and Andrew W. Taylor-Robinson ${ }^{2 *}$ \\ ${ }^{1}$ Sustainable Innovation, School of Business \& Law, Central Queensland University, Brisbane, QLD, Australia, ${ }^{2}$ Infectious \\ Diseases Research Group, School of Health, Medical \& Applied Sciences, Central Queensland University, Brisbane, QLD, \\ Australia
}

Keywords: COVID-19, dengue, transmission, culture, religion, gender, traditional clothing, facial touching

\section{OPEN ACCESS}

Edited by:

Zisis Kozlakidis,

International Agency for Research on

Cancer (IARC), France

Reviewed by:

Yunchang Shao,

China National GeneBank

(BGl), China

*Correspondence:

Andrew W. Taylor-Robinson

a.taylor-robinson@cqu.edu.au

Specialty section:

This article was submitted to

Infectious Diseases - Surveillance,

Prevention and Treatment,

a section of the journal

Frontiers in Public Health

Received: 04 April 2020

Accepted: 21 April 2020

Published: 30 April 2020

Citation:

Muurlink OT and Taylor-Robinson AW (2020) COVID-19: Cultural Predictors

of Gender Differences in Global

Prevalence Patterns.

Front. Public Health 8:174.

doi: 10.3389/fpubh.2020.00174
Puzzling differences are emerging between male and female infection and death rates for COVID-19 (1). We predict that this may be amplified, especially in the developing world, due to hitherto overlooked cultural factors. Currently, credible data from low- and lower middle-income countries on COVID-19 are sparse, with recorded case numbers seemingly suppressed by unreliable surveillance, lesser testing capacity and an underlying burden of infectious diseases that may mimic key symptoms, notably pyrexia. Indeed, acute undifferentiated febrile illness is a common feature of resource-limited tropical regions. Patterns of prevalence of vector-borne diseases in the developing world, however, offer an indication of likely COVID-19 infection and morbidity gender trends.

Cultural factors, in particular the extent to which long or "modest" clothing is worn and the convention of separating adults by gender, may inadvertently determine the rapidity and extent of the spread of communicable diseases including COVID-19. A study of six Asian countries on the prevalence of dengue showed a striking tendency toward greater infection rates for males compared to females, but only for those aged 15 or over for whom cultural differences in work patterns outside the home, social interaction and dress all apply (2). This disparity is plausibly explained as a difference in exposure to the mosquito vector and is linked to established recommendations on wearing protective clothing. However, it is noteworthy that in Brazil, where standards of modesty for male and female clothing are equivalent (3), this gender difference in dengue incidence disappears (4).

Cultures that place greater restrictions on the movement and dress of women are likely to see fewer opportunities for both vector- and air-borne pathogen transmission for women relative to men. One of the known routes of infection with SARS-CoV-2 is touching one's face, leading to public health agency advisories against this practice $(5,6)$. This presents a challenge to community education since this behavior is instinctive (7), habitual and very frequent (8). Yet, in conservative Muslim cultures in particular, where wearing a burka or niqab, providing full or partial coverage of the face, respectively, is relatively common in public, touching of mouth, nose and eyes by females is correspondingly restricted. Even in the increasingly observed instances of where the "modesty" function of covering the hair and face is separated from the traditional (often religious) purpose of the clothing (9), such practices have this unintended public health value. Facial covering additionally affords a limited level of filtration of air-borne droplets (10), such as those carrying virus particles. In contrast, the cultural predilection for facial hair among male Muslims is likely to further increase male exposure to the virus, particularly amongst health professionals where facial hair compromises the seal of P2/N95-standard particulate filtering respirators and surgical masks (11).

In a recent analysis of gender and COVID-19, a working group argued that "policies and health impacts have not addressed the gendered impacts of disease outbreaks" (12), but the interaction between gender roles and disease exposure was overlooked in their analysis. In other cultures, or 
indeed subcultures, where versions of the veil or other passive forms of discouragement of facial touching are absent, but where strict or partial segregation of genders is observed due to cultural norms (e.g., among Amish communities in the United States, or in Orthodox Jewish communities in Israel) $(13,14)$ pathways to community transmission are likely to be impinged. Of course, more highly-segregated workforces and family life is seen in traditional societies regardless of the prevalent religion or other belief system.

The segregation between genders is apparent even in industrialized nations, albeit less overtly, where it impacts on the involvement of women in society itself (such as the extent to which females engage in certain occupations or roles outside the home) [e.g., $(15,16)]$. This lower level of engagement in society beyond the customary domestic and childcare functions may even, in extreme cases, reduce the likelihood of women attending a health clinic to receive a diagnosis (and treatment), leading to underreporting of diseases among adult females. For instance, in rural and remote regions there is often a gender imbalance in favor of male medical practitioners (17). In combination with strong cultural inhibitors that are frequently prevalent in isolated communities toward women interacting with men outside their family group (18), women may not expressly seek medical attention.

\section{REFERENCES}

1. Cai H. Sex difference and smoking predisposition in patients with COVID-19. Lancet Respir Med. (2020) 8:e20. doi: 10.1016/S2213-2600(20)30117-X

2. Anker M, Arima Y. Male-female differences in the number of reported incident dengue fever cases in six Asian countries. Western Pac Surveill Response J. (2011) 2:17. doi: 10.5365/wpsar.2011.2.1.002

3. Hussain A. Carnival Reveals Much About Gender, Sexuality, and Culture in Brazil. (2013). Available online at: https://berkleycenter.georgetown.edu/ posts/carnival-reveals-much-about-gender-sexuality-and-culture-in-brazil (accessed April 19, 2020).

4. da Glória Teixeira M, da Conceição Nascimento Costa M, Guerra Z, Barreto ML. Dengue in Brazil: situation - 2001 and trends. Dengue Bull. (2002) 26:70-6.

5. Centers for Disease Control and Prevention. Coronavirus Disease 2019 (COVID-19). How to Protect Yourself and Others. (2020). Available online at: https:/www.cdc.gov/coronavirus/2019-ncov/prevent-getting-sick/ prevention.html (accessed April 19, 2020).

6. World Health Organization. Coronavirus Disease (COVID-19) Advice for the Public. (2020). Available online at: https://www.who.int/emergencies/ diseases/novel-coronavirus-2019/advice-for-public (accessed April 19, 2020).

7. Suarez SD, Gallup GG. Jr. Face touching in primates: a closer look. Neuropsychologia. (1986) 24:597-600. doi: 10.1016/0028-3932(86)90105-3

8. Benning SD, Labus B, Barchard KA. How to stop Touching Your Face to Minimize Spread of Coronavirus and Other Germs. The Conversation 19 March (2020). Available online at: https://theconversation.com/how-to-stoptouching-your-face-to-minimize-spread- of-coronavirus-and-other-germs133683 (accessed April 19, 2020).

9. Sobh R, Belk RW, Gressel J. Modest seductiveness: reconciling modesty and vanity by reverse assimilation and double resistance. J Consum Behav. (2012) 11:357-7. doi: $10.1002 / \mathrm{cb} .1379$

10. Rengasamy S, Eimer B, Shaffer RE. Simple respiratory protection - evaluation of the filtration performance of cloth masks and common fabric materials against 20-1000 nm size particles. Ann Occup Hyg. (2010) 54:789-98. doi: 10.1093/annhyg/meq044

11. Sandaradura I, Goeman E, Pontivivo G, Fine E, Gray H, Kerr S, et al. A close shave? Performance of $\mathrm{P} 2 / \mathrm{N} 95$ respirators in healthcare workers with facial
Here, we argue that cultural factors may impact on the gender balance of reported COVID-19 infection prevalence in systematic ways, particularly in conservative societies, whether religious or secular, around the world. This is to say: women may be afforded some protection by customs relating to traditional clothing; they may be placed at less risk of contracting infection through distancing from men or separation from the broader workforce and community; and - by their known reluctance to be attended by a male medical practitioner and so be less disposed to seek a qualified diagnosis - they may be underrepresented in data collected on infection and morbidity.

\section{AUTHOR CONTRIBUTIONS}

OM and AT-R made substantial contributions to the conception of the work and to literature search, contributed significantly to writing the manuscript, revised it critically for important intellectual content, approved its final version, and agreed to its submission.

\section{FUNDING}

Frontiers has waived Article Processing Charges (APCs) and established a priority peer-review process for manuscripts submitted in response to the COVID-19 pandemic.

hair: results of the BEARDS (BEnchmarking Adequate Respiratory DefenceS) study. J Hosp Infect. (2020) 104:529-33. doi: 10.1016/j.jhin.2020.01.006

12. Wenham C, Smith J, Morgan R, Gender COVID-19 Working Group COVID-19: the gendered impacts of the outbreak. Lancet. (2020) 395:846-8. doi: 10.1016/S0140-6736(20)30526-2

13. Johnson-Weiner $\mathrm{K}$. The role of women in old order Amish, beachy Amish and fellowship churches. Mennonite Q Rev. (2001) 75:231-57.

14. Warburg AY. The practice of gender separation on buses in the ultra-orthodox community in Israel: a view from the Liberal cathedral. Tradit J Orthodox Jewish Thought. (2011) 44:19-29.

15. Timmis AD, Baker C, Banerjee S, Calver AL, Dornhorst A, English $\mathrm{KM}$, et al. Women in UK cardiology: report of a Working Group of the British Cardiac Society. Heart. (2005) 91:283-9. doi: 10.1136/hrt.2004. 047340

16. Berecki-Gisolf J, Lucke J, Hockey R, Dobson A. Transitions into informal caregiving and out of paid employment of women in their 50s. Soc Sci Med. (2008) 67:122-7. doi: 10.1016/j.socscimed.2008.03.031

17. Wainer J, Bryant L, Strasser R. Sustainable rural practice for female general practitioners. Aust J Rural Health. (2001) 9(Suppl. 1):S43-8. doi: 10.1046/j.1440-1584.9.s1.3.x

18. Chaudhury N, Hammer JS. Ghost doctors: absenteeism in Bangladeshi health facilities (2003). The World Bank: Policy Research Working Paper, Report Number WPS3065. Available online at: http://documents.worldbank. org/curated/en/391671468741863285/Ghost-doctors-absenteeism-inBangladeshi-health-facilities (accessed April 19, 2020).

Conflict of Interest: The authors declare that the research was conducted in the absence of any commercial or financial relationships that could be construed as a potential conflict of interest.

Copyright $\odot 2020$ Muurlink and Taylor-Robinson. This is an open-access article distributed under the terms of the Creative Commons Attribution License (CC BY). The use, distribution or reproduction in other forums is permitted, provided the original author(s) and the copyright owner(s) are credited and that the original publication in this journal is cited, in accordance with accepted academic practice. No use, distribution or reproduction is permitted which does not comply with these terms. 